\title{
First record of the subgenus Damaeus (Paradamaeus) Bulanova-Zachvatkina (Oribatida, Damaeidae) from China, with description of a new species
}

\author{
Lixia Xie ${ }^{1, \dagger}$, Yi Yan ${ }^{1, \neq}$, Rong Huang ${ }^{1, \S}$, Maofa Yang ${ }^{1,1}$ \\ I Institute of Entomology, Guizhou University; The Provincial Key Laboratory for Agricultural Pest Manage- \\ ment of Mountainous Region, Guiyang, Guizhou, P. R. China, 550025 \\ † urn:lsid:zoobank.org:author:6E8D796C-AF36-4230-AC7B-61CD9D9E0BB7 \\ † urn:lsid:zoobank.org:author:7E765972-6256-48D1-8341-F150DF70D38D \\ § urn:lsid:zoobank.org:author:687D26EC-CD49-43D5-8B02-8D62BCB67A22 \\ | urn:lsid:zoobank.org:author:79B3BA54-5CBD-43CD-B50C-FAABBBFA4904 \\ Corresponding author: Maofa Yang (yangmaofa@sohu.com)
}

Academic editor:A. Bochkov | Received 29September 2011| Accepted 11 November 2011 | Published 29 December 2011

urn:lsid:zoobank.org:pub:0F04DD1D-A24E-4E08-B62A-90F1AEE57895

Citation: Xie L, Yan Y, Huang R, Yang M (2011) First record of the subgenus Damaeus (Paradamaeus) BulanovaZachvatkina (Oribatida, Damaeidae) from China, with description of a new species. ZooKeys 160: 47-57. doi: 10.3897/ zookeys. 160.2160

\begin{abstract}
A new species Damaeus (Paradamaeus) yushuensis sp. n. is described from Three Rivers' Headwaters National Natural Reserve, Qinghai province, China. This is the first record of this subgenus in China. A key is given to distinguish all species of the genus.
\end{abstract}

\section{Keywords}

Oribatida, Damaeus, Paradamaeus, new species, new record

\section{Introduction}

Bulanova-Zachvatkina (1957) proposed Paradamaeus to be a subgenus of Damaeus with Damaeus (Paradamaeus) clavipes Hermann, 1804 as type species, which is only single known species in the world. The diagnosis of this subgenus as given by Bulanova-

Copyright Lixia Xie et al. This is an open access article distributed under the terms of the Creative Commons Attribution License 3.0 (CC-BY), which permits unrestricted use, distribution, and reproduction in any medium, provided the original author and source are credited. 
Zachvatkina (1957): large body size; rugged prodorsum with distinct ridges; apophysis $P$ well developed; interlamellar setae(in) much shorter than sensillus (ss); prodorsal tubercles $D a, B a$ and $B p$ present; spinae adnatae (s.a.) well developed; companion seta $d$ lost on genu III; setation of genua 4-4-2-3.

We firstly recorded the species of Paradamaeus from Three Rivers' Headwaters National Natural Reserve, Qinghai, China, which represented as new species, Damaeus (Paradamaeus) yushuensis. A key to the identification of all known species of Damaeus (Paradamaeus) is given.

\section{Material and methods}

Measurements and descriptions are based on specimens mounted in temporary cavity slides that were studied using a standard light microscope equipped with a drawing tube. In figures we used the following abbreviations: prodorsal and sejugal apophyses $(B a, B p)$, lateral apophyses $(S a, S p)$ and coxisternal apophyses $(E 2 a$, $E 2 p, V a, V p$ ), spina adnatum (s.a.), discidium (di), prodorsal setae (ro, le, in, ex), bothridium (bo), sensillus (ss), notogastral or gastronotal setae (c-, l-, $h$-, $p$ - series), adanal and anal setae ( $a d-$, $a n$ - series), aggenital setae (ag), coxisternal setae ( $1 a, 1 b$, $1 c, 2 a, 3 a, 3 b, 3 c, 4 a, 4 b, 4 c, 4 d)$, opisthonotal gland opening (gla), lyrifissures or cupules ( $i a, i m, i p$, ian, iad, ips, ih).

Terminology generally follows Grandjean (1949, 1954b, 1960), Miko (2006) and Norton \& Behan-Pelletier (2009). The unit of measurement is micrometre $(\mu \mathrm{m})$. All type specimens and other material studied are kept in alcohol and deposited in the Institute of Entomology, Guizhou University, Guiyang, China (GUGC).

\section{Taxonomy}

\section{Damaeus (Paradamaeus) clavipes (Hermann, 1804)}

Notaspis clavipes: Hermann 1804; Grandjean 1936, 1954a; Hammen 1952; Sellnick 1960.

Oribata clavipes: Oudemans 1900; Kulczyński 1902; Sellnick 1928.

Belba clavipes: Willmann 1931; Grandjean 1935; Schweizer 1956.

Damaeus (Paradamaeus) clavipes: Bulanova-Zachvatkina 1957; Balogh \& Balogh 1992;

Pérez-Í́nigo 1997; Subías 2004; Miko 2006.

Paradamaeus clavipes: Bulanova-Zachvatkina 1967, 1975; Schatz 1983; Siepel 1996.

Distribution. China, Germany, Ireland, Southern Mediterranean, Faroe Islands, Norway, Latvia, Caucasus, Crimea, Ukraina, Czechoslovakia, Czech Republic, Belgium, Sweden, England, America, Finland, Azores Islands, France, Austria, Netherlands. 


\section{Keys to species of Damaeus (Paradamaeus).}

1 With dorsosejugal tubercles $D a, D p$; setae in short and thin; notogastral setae similar to one another ........................... Damaeus (Paradamaeus) clavipes

- $\quad$ Without dorsosejugal tubercles $D a, D p$; setae in long and thick; notogastral setae not similar to one another

.Damaeus (Paradamaeus) yushuensis sp. n. (Figs 1-6)

\section{Damaeus (Paradamaeus) yushuensis sp. $\mathbf{n}$.} urn:Isid:zoobank.org:act:9CA2E39F-5E98-43B2-87D5-DDD3F4119690 http://species-id.net/wiki/Damaeus_yushuensis Figs 1-6

Material examined. Holotype: male (in alcohol, QHYS-XLX-8-5), China, Three Rivers' Headwaters Natural Reserve Area of Yushu Tibetan Autonomous Prefecture, Qinghai province $\left(32^{\circ} 33^{\prime} 48.65^{\prime \prime} \mathrm{N}, 97^{\circ} 39^{\prime} 55.66^{\prime \prime E}\right)$, from soil under the Picea crassifolia, 3464M, 5 Aug., 2009, col. Lixia Xie. Paratypes: Three females (in alcohol, QHYS-XLX-8-5), same data as holotype; Two males (in alcohol, QHYS-XLX-8-6), same data as QHYS-XLX-8-5, from soil under the Kobresia pygmaea.

Diagnosis. Propodolateral apophysis $P$ distinct, with broader base and arched tip; setae ro slightly barbed, setae le heavily barbed, thick. Sensillus short, thick, heavily barbed and rod-like. Interlamellar setae long, rather thick and conspicuously barbed. Prodorsal tubercles $D a, D p$ absent, $B a$ well developed, $B p$ weakly developed. Spinae adnatae beak like, short, distinct, strongly curved inwards (about $30 \mu \mathrm{m}$ in total), with broader base and quite sharp tip. Notogastral setae smooth, slender except $c$ - series and $p$ - series. Setae of $c$ - series rather thick, with conspicuously barbed and frizzled tip, oriented forwards and the rest backwards.

Comparative length of notogastral setae: $l p<l m=p s 3<p s 2<l a=h_{3}=h_{2}=h_{1}<p s 1<$ $c_{1}<c_{2}$. Epimeral setae mostly smooth except $1 b, 1 c, 3 b, 3 c, 4 d$ and hypostomal setae $a$, $m$, h. Seta $1 a, 2 a$ and $3 a$ rather short. Epimeral setal formula: 3-1-3-4. Enantiophyses $E 2$ and $V$ present, E2p and $V p$ weakly developed, E2a and $V a$ well developed. Parastigmatic tubercle $S a$ long, acuminate, with sharp tip; $S p$ small, triangular. Hypostomal setae $a, h$ and $m$ thin, slightly barbed. Legs rod-like and longer than body.

Description of adult. Dimensions. Holotype: Body length 980; length of prodorsum: 420 , width 280 , height 370 , setae: ss 175 , in 100 , le 150 , ro 125 , ex 75 , distance between setae: ro-ro 110, in-in 125, le-le 125, in-le 105, le-ro 40; length of notogaster: 700 , width 670 , height 780; setae: $c 1$ 135, $c 2175$, la 110, lm 95, lp 90 , h3 110, h2 110, h1 110, ps1 125, ps2 105, ps3 95; c1-c2 75, c2-c2 275, la-la 375, lmIm 435; ventral region: genito-aggenital plate $225 \times 220$, ano-adanal plate $190 \times 175$. Paratypes: length of prodorsum: 415-425, width 275-285, height 365-375; length of notogaster: 695-705, width 665-670, height 775-780; ventral region: genito-aggenital plate $220 \times 215$, ano-adanal plate $185 \times 170$. 


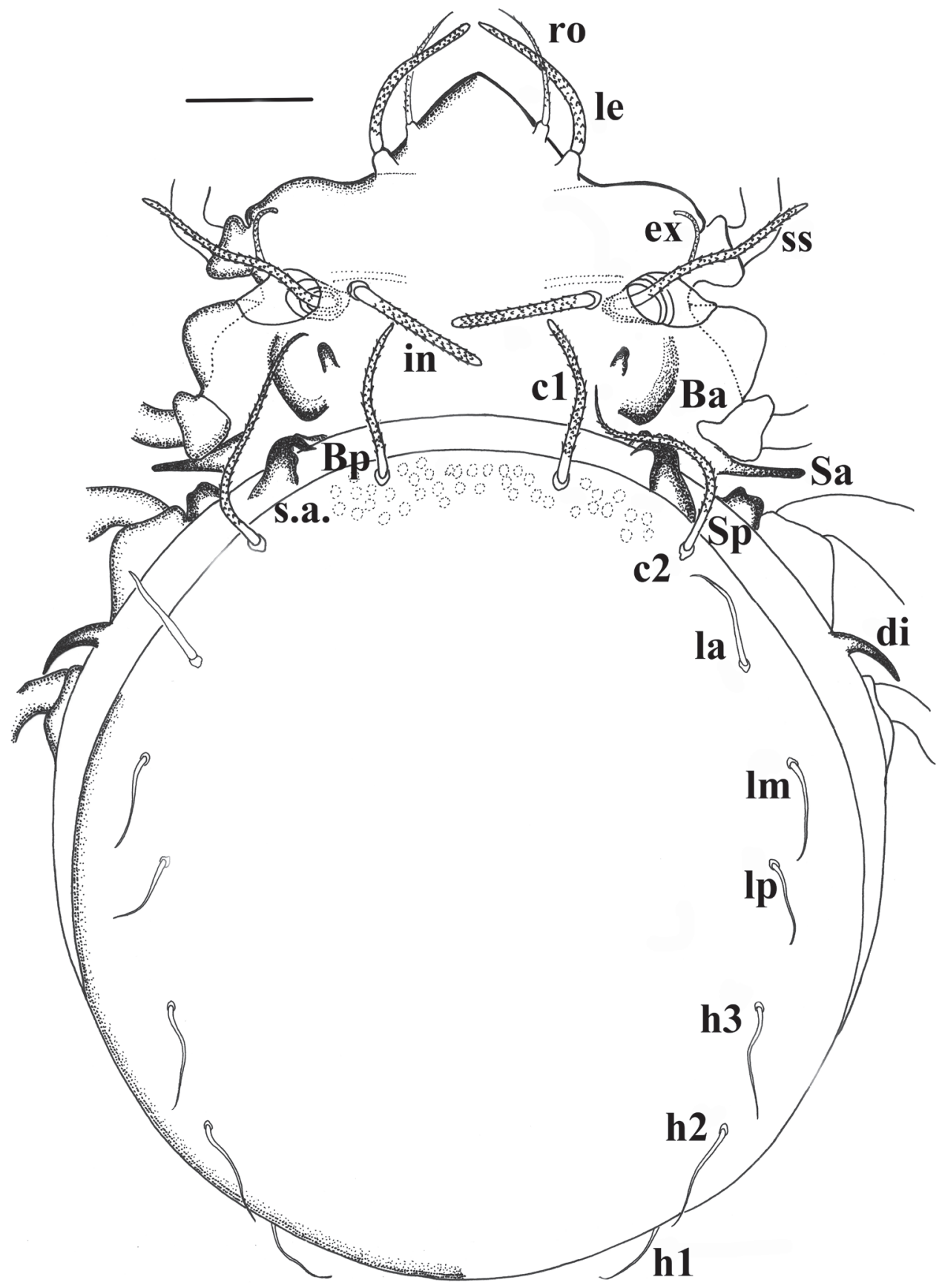

Figure I. Damaeus (Paradamaeus) yushuensis sp. n.- dorsal view $(100 \mu \mathrm{m})$ 


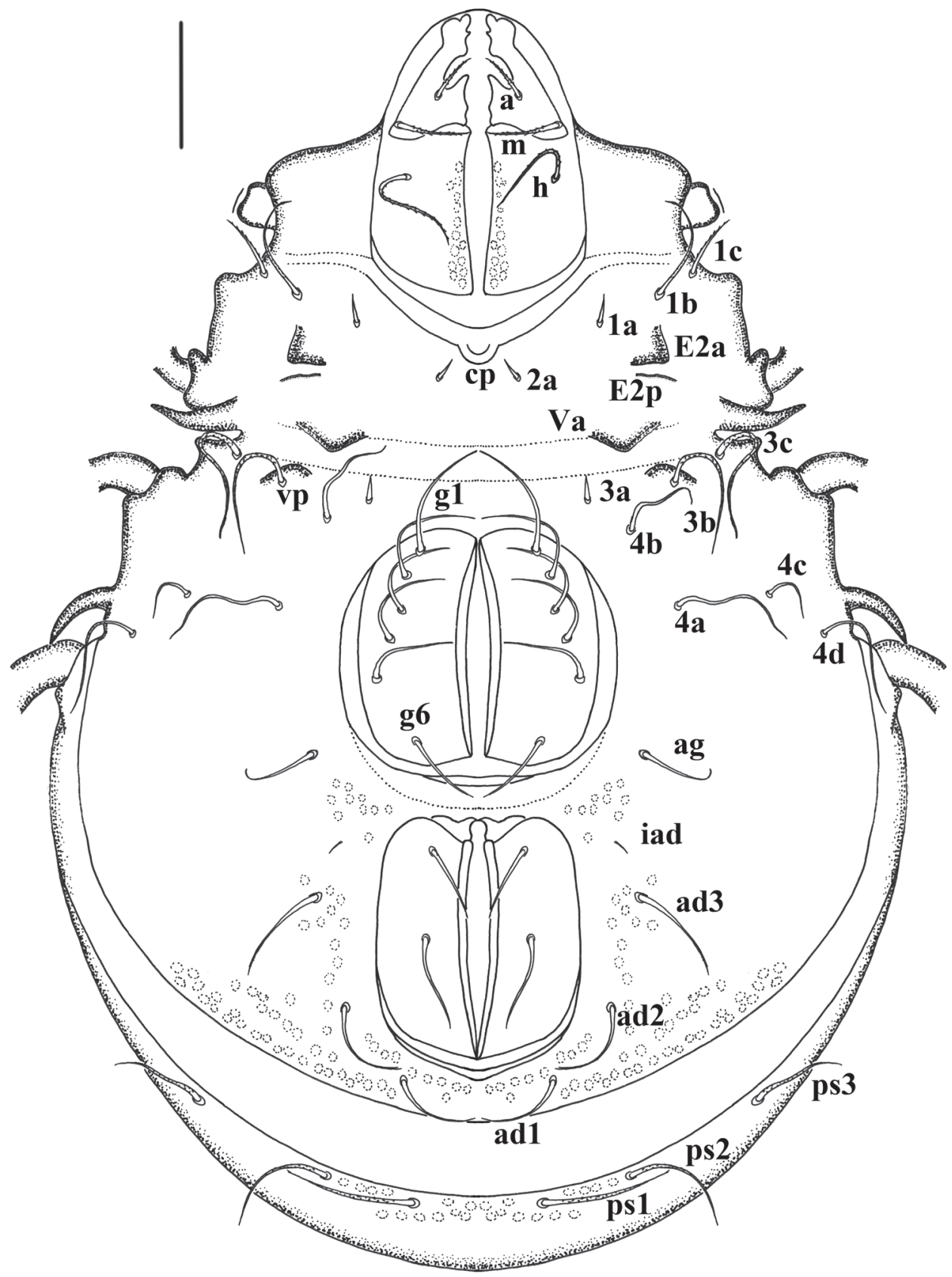

Figure 2. Damaeus (Paradamaeus) yushuensis sp. n. - Ventral view $(100 \mu \mathrm{m})$ 


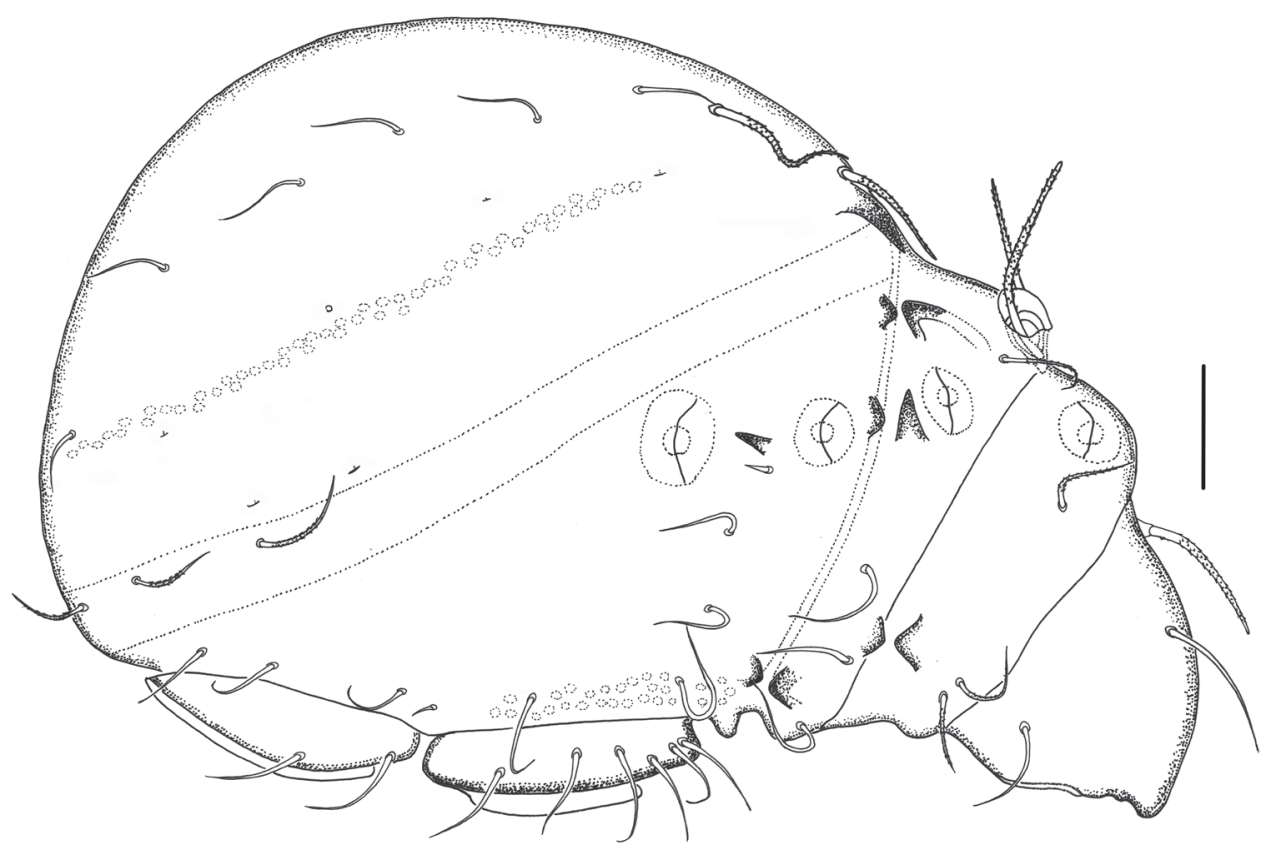

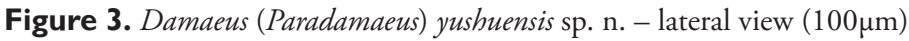

Integument. Surface of body and leg segments with filamentous cerotegument. Conspicuous microtubercles present on prodorsum and around leg acetabula, legs with dense fungal mycelic.

Prodorsum (Fig. 1). Triangular, propodolateral apophysis $P$ distinct, with broader base and arched tip. Lamellar setae (le) and rostral setae (ro) both in dorsalaterad position, long, arched and tapered. Lamellar setae with obvious barbs, thick, being longer than slender, weakly barbed rostral pair. Bothridia well developed, funnel-like, with broad margin and pair of thick, heavily barbed sensillus. Interlamellar setae (in) long, thick and conspicuously barbed (specially in holotype). Exobothridial setae (ex) thick, with obvious barbs, frizzled. Comparative length of prodorsal setae: $e x<$ in $<r o<l e<s s$. Weakly developed transverse ridge connected to the base of bothridium and directed to median end of prodorsum. Prodorsal tubercles $D a$ absent, $B a$ distinct; $B p$ weakly developed, usually as tuberculate sclerotised ridge, in light microscope sometimes discernible only in lateral view.

Notogaster. (Fig. 1). Circular viewed perpendicular to circumgastric scissure, length almost equivalent to wider. Spinae adnatae beak like, short, distinct, strongly curved inwards (about $30 \mu \mathrm{m}$ in length), with broader base and quite sharp tip. Notogastral setae short, smooth, slender except $c$ - series and $p$ - series. Setae of $c$ - series rather thick and long, with conspicuous barbed and frizzled tip, oriented forwards and the rest backwards. Comparative length of notogastral setae: $l p<l m=p s 3<p s 2<l a=h 3=h 2=h 1<$ $p s 1<c 1<c 2$. Pseudanal setae comparatively long, with obvious barbs, attenuate. 


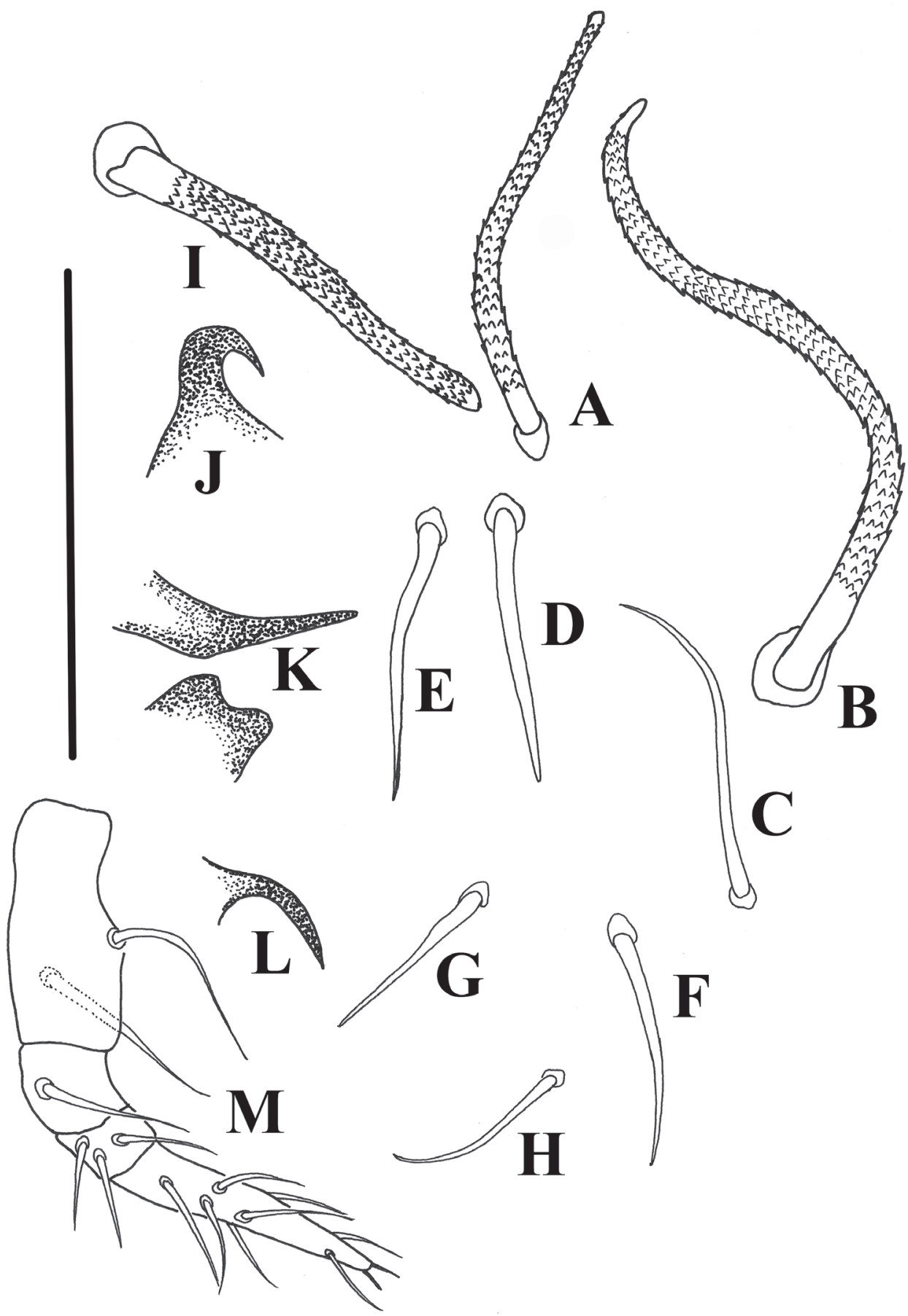

Figure 4. Damaeus (Paradamaeus) yushuensis sp. n. A-H notogastral setae $(100 \mu \mathrm{m})$ I interlamellar seta $(100 \mu \mathrm{m}) \mathbf{J}$ s.a.-spina adnata $(100 \mu \mathrm{m}) \mathbf{K}$ Sa -anterior sejugal apophysis $(100 \mu \mathrm{m}), \mathrm{Sp}$-posterior sejugal apophysis $(100 \mu \mathrm{m}) \mathbf{L}$ di - discidium $(100 \mu \mathrm{m}) \mathbf{M}$ Pe. - pedipalp $(100 \mu \mathrm{m})$. 


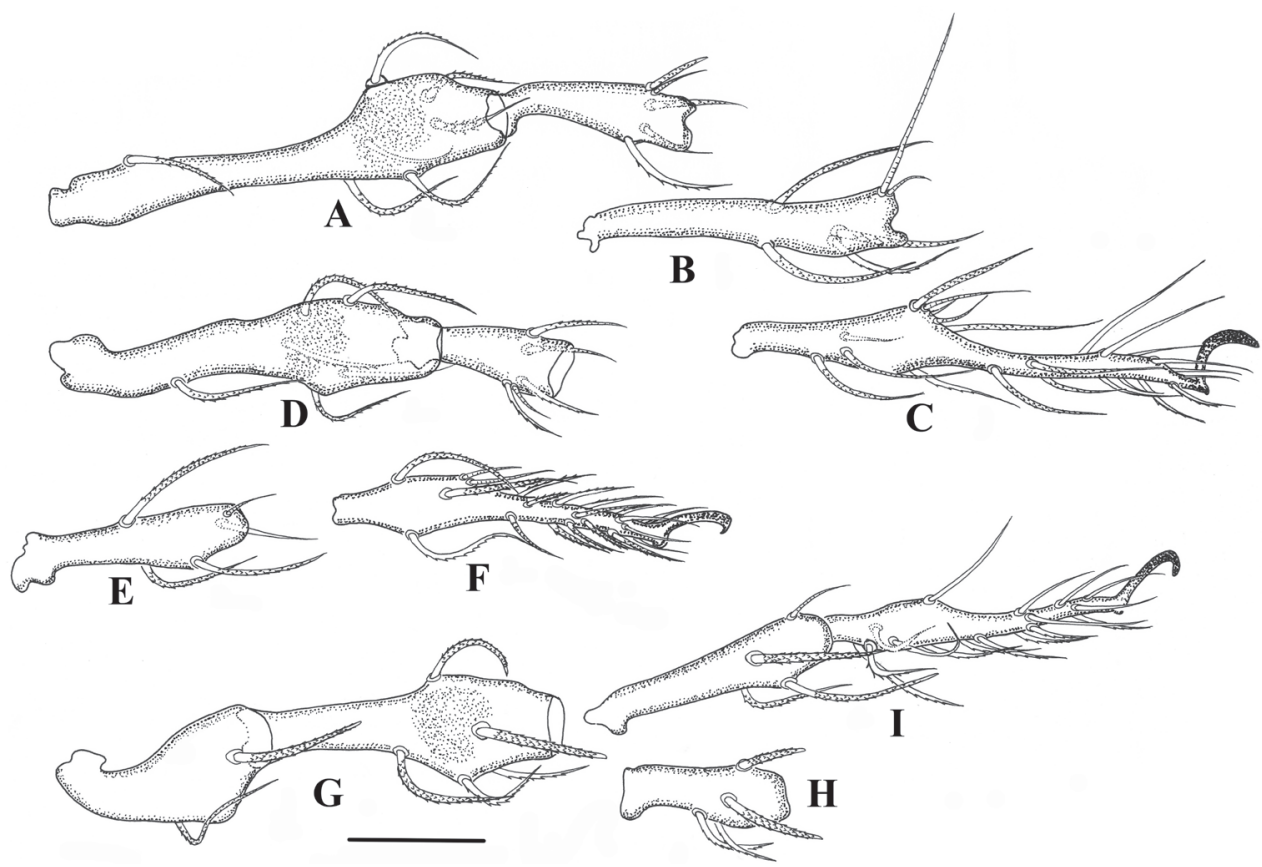

Figure 5. Damaeus (Paradamaeus) yushuensis sp. n. A femur, genu I $(100 \mu \mathrm{m})$ B tibia I $(100 \mu \mathrm{m}) \mathbf{C}$ tarsus I $(100 \mu \mathrm{m}) \mathbf{D}$ femur, genu II $(100 \mu \mathrm{m}) \mathbf{E}$ Tibia II $(100 \mu \mathrm{m}) \mathbf{F}$ tarsus II $(100 \mu \mathrm{m}) \mathbf{G}$ trochanter, femur III $(100 \mu \mathrm{m}) \mathbf{H}$ genu III $(100 \mu \mathrm{m}) \mathbf{I}$ tibia, tarsus III $(100 \mu \mathrm{m})$.

Ventral region. (Fig. 2). Epimere I with medial pit (cp). Epimeral setae mostly smooth except $1 b, 1 c, 3 b, 3 c, 4 d$; setae $1 c, 3 b, 3 c, 4 d$ long, with obvious barbs; Seta $1 a$, $2 a$ and $3 a$ rather short, lanciform. Epimeral setal formula: 3-1-3-4. Ano-genital setal formula: 6-1-2-3. Enantiophyses $E 2$ and $V$ present, $E 2 a$ triangular with pointed tip; $E 2 p$ weakly developed, usually as tuberculate sclerotised ridge. Ventrosejugal tubercle $\mathrm{Va}$ large, strong, represented by broad ridge; $V p$ represented by low, broadly curved ridge, with setae $3 b$ Parastigmatic tubercle $S a$ long, acuminate, with broader base and heavily pointed tip; $S p$ small, triangular; Discidium ( $d i)$ long, acuminate, with broader base and heavily pointed tip, directed posterolaterad.

Gnathosoma. Infracapitular mentum without noticeable microtubercles. Hypostomal setae $a, m, h$ slender, weakly barbed. Chelicera rather strong, fixed and movable digits with four blunt teeth; setae $c h a$ with obvious barbs and $c h b$ smooth. Palpal setation: $0-2-1-3-8$, including solenidion $\omega$ (Fig. 4M).

Legs. (Figs 5-6). Monodactylous, moderately long, leg I, III, IV longer than body, leg II shorter than body. Relative length of femur to tarsus of legs I to IV 1: 0.88: 1.01: 1.2. Leg IV 1.3 times ventral body length. Femur IV 1.4 times length of trochanter IV, proximal stalk 1.4 times length of bulb. Leg setae medium in length and thick, mostly with distinct short barbs on outer curvature. Setal formulas of legs as follows (from trochanter to tarsus, famulus and solenidia included): I: $1-7-4$ (1) -4 (2)-20 (2); II: 1-6-4 (1)-4 (1)-18 (2); III: 2-4-3 (1)-3 (1)-16 (0); IV: 1-4-3 (1)-3 (1)-15 (0). Solenidia of genua I-II with compan- 


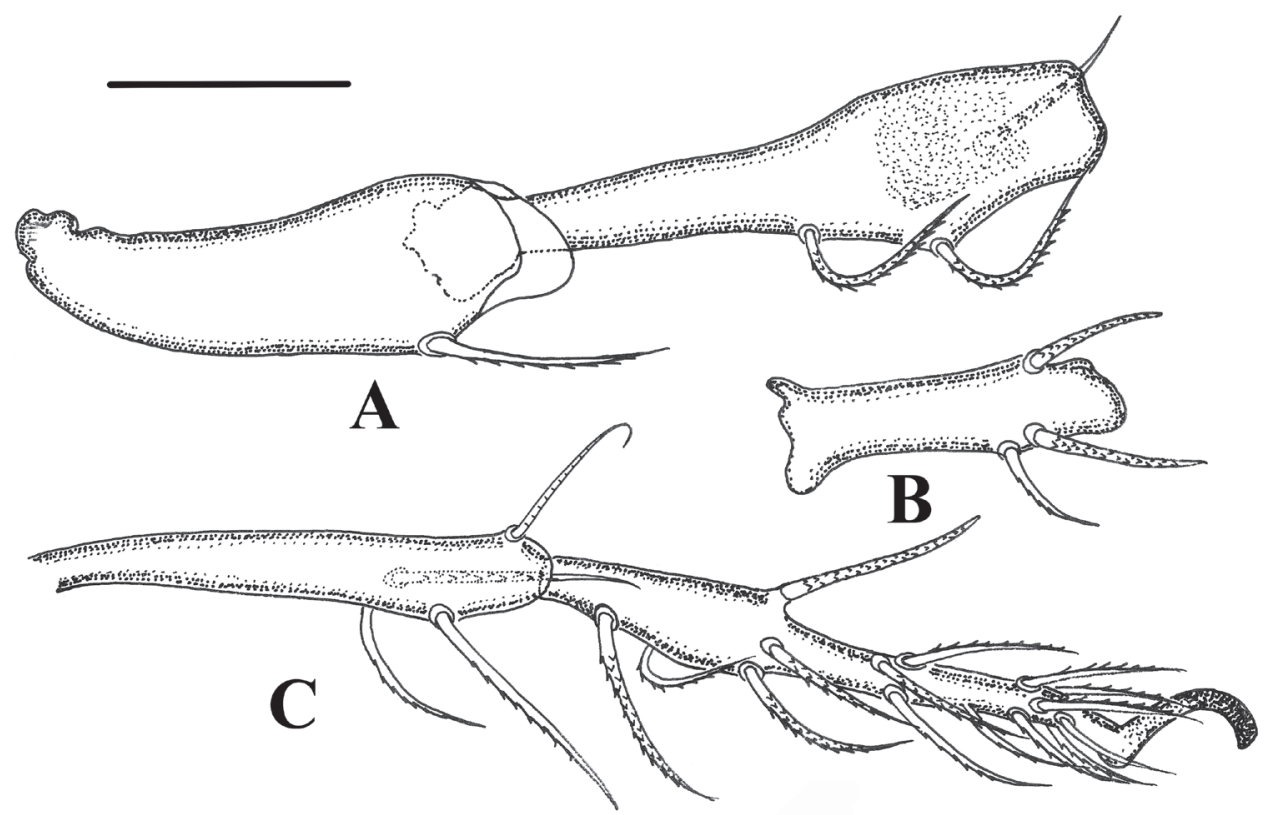

Figure 6. Damaeus (Paradamaeus) yushuensis sp. n. A trochanter, femur IV $(100 \mu \mathrm{m})$ B genu IV $(100 \mu \mathrm{m})$ C tibia, tarsus IV $(100 \mu \mathrm{m})$.

ion seta $d$. Solenidia $\delta$ equivalent to seta $d$ on genua I, Solenidia $\delta$ shorter and thinner than seta $d$ on genua II. Solenidion $\varphi 1$ on tibia I 3 times longer than $\varphi 2$. Seta $d$ absent from all tibiae, solenidia on all tibiae free, as usual for genus.

Etymology. The specific name is derived from the type locality, Yushu Tibetan Autonomous Prefecture, Qinghai province.

Remarks. This new species is characterised by following characters: interlamellar setae (in) long, rather thick and conspicuously barbed; spinae adnatae beak like, short, distinct, strongly curved inwards; $c$-series rather thick, long with conspicuous barbed and frizzled tip, oriented forwards and the rest backwards, other notogastral setae smooth, slender and short, except $p$ - series (see Table 1).

Table I. Comparison of two species belonging to the subgenus Paradamaeus

\begin{tabular}{l|l|l}
\hline Morphological character & D. (Paradamaeus) clavipes & $\begin{array}{l}\text { D. (Paradamaeus) yushuensis } \\
\text { sp. n. }\end{array}$ \\
\hline propodolateral apophysis $P$ & with angular tip & with arched tip \\
\hline Interlamellar setae (in) & short, thin & long, thick \\
\hline Spinae adnatae (s.a.) & $\begin{array}{l}\text { slender, medium long, } \\
\text { triangular with sharp tip }\end{array}$ & beak like, short, quite sharp tip \\
\hline Notogastral setae $c 1, c 2$ & similar in length, slender & unequal length, thick \\
\hline Number of setae on Femora III-IV & 5 & 4 \\
\hline Prodorsal tubercles $D a, D p$ & present & absent \\
\hline Parastigmatic tubercle $S a$ & small, indistinct & $\begin{array}{l}\text { large, acuminate, with broader } \\
\text { base and heavily pointed tip }\end{array}$ \\
\hline
\end{tabular}




\section{Acknowledgements}

The authors are very grateful to Prof. Roy A. Norton (College of Environmental Science and Forestry, State University of New York, Syracuse) for his encouragement to our research and kind help. The authors are also grateful to Dr. Owen Seeman (Queensland Museum, South Brisbane, Australia) and Dr. Sergey G. Ermilov (Laboratory of Entomology, Center of Independent Examinations, Nizhniy Novgorod, Russia) for their help. We are very grateful to Qiongzhang Song, Fangling Xu, Zaihua Yang, Bin $\mathrm{Li}$ (Institute of Entomology, Guizhou University, Guiyang, Guizhou province, China) for making it possible to work by their collections.

\section{References}

Balogh J, Balogh P (1992) The oribatid mites genera of the world. The Hungarian National Museum Press, Budapest vol. 1, 263 pp., vol. 2, 375 pp.

Bulanova-Zachvatkina, EM (1957) Mites of the family Damaeidae Berl. (Acariformes; Oribatei), ${ }^{\text {st }}$ information. Zoologicheskij Zhurnal 36: 1167-1186. [in Russian]

Bulanova-Zachvatkina EM (1967) Oribatid mites - Oribatida. Vysshaya Shkola Publishers, Moscow, 254 pp. [In Russian]

Bulanova-Zachvatkina EM (1975) Family Damaeidae Berlese, 1896. In: Ghilarov MS (Ed) Key to soil-inhabiting mites -Sarcoptiformes. Nauka, Moskva, 121-131. [in Russian]

Grandjean F (1935) Observations sur les acariens (ler serie). Bulletin du Museum D'Histoire naturelle 7(2): 119-126.

Grandjean F (1936) Les oribates de Jean Fredéric Hermann et de son pere (Arachn. Acar.). Annales de la Société Entomologique de France 105: 27-110.

Grandjean F (1949) Formules anales, gastronotiques, génitales et aggénitales du développement numérique des poils chez les Oribates. Bulletin de la Société Zoologique de France 74: 201-225.

Grandjean F (1954a) Observations sur les Oribates (30e série). Bulletin du Museum D’Histoire naturelle 26(2): 482-490.

Grandjean F (1954b) Essai de classification des Oribates (Acariens). Bulletin de la Société Zoologique de France 78: 421-446.

Grandjean F (1960) Damaeus avernensis n. sp. (Oribate). Acarologia 2: 250-275.

Hammen L van der (1952) The Oribatei (Acari) of the Netherlands. Zoologische Verhandelingen 17: 1-139.

Hermann JF (1804) Memoire apterologique. Strassbourg, 144 pp.

Kulczyński M (1902) Species oribatinarum (Oudms.) (Damaeinarum Michael) in Galicia collectae. Bulletin International de L'Académie des Sciences de Cracovie, Classe des sciences mathématiques et naturelles 2: 89-96.

Marshall VG, Reeves RM, Norton RA (1987) Catalogue of the Oribatida (Acari) of Continental United States and Canada. Memoirs of the Entomological Society of Canada 139: $1-418+6$. 
Miko L (2006) Damaeidae. In: Weigmann G (Ed) Hornmilben (Oribatida), Die Tierwelt Deutschlands, Teil 76. Goecke \& Evers, Keltern, 179-207.

Norton RA, Behan-Pelletier VM (2009) Suborder Oribatida. In: Krantz GW, Walter DE (Eds) A Manual of Acarology. Texas Tech University Press, Lubbock, 430-564.

Oudemans AC (1900) New list of Dutch Acari. lst part. Tijdschrift voor Entomologie 43: $150-171$.

Pérez-Íñigo C (1997) Acari. Oribatei. Gymnonota I. In: Ramos A et al. (Eds) Fauna Iberica. Museo de Ciencias Naturales, Madrid, vol. 9, 1-373.

Schatz H (1983) U.-Ordn. Oribatei, Hornmilben. Catalogus faunae Austriae. Ein systematisches Verzeichnis aller auf österreichischem Gebiet festgestellten Tierarten, 9, Österreichische Akadademie der Wissenschaften, Wien, 118 pp.

Schweizer J (1956) Die Landmilben des Schweizerischen Nationalparkes. 3. Teil, Sarcoptiformes Reuter 1909. Ergebnisse der wissenschaftlichen Untersuchungen im Schweizerischen Nationalpark (Neue Folge) 5(34): 213-377.

Sellnick M (1960) Formenkreis: Hornmilben, Oribatei. In: Brohmers P, Ehrmann P, Ulmerm G (Eds) Die Tierwelt Mitteleuropas Vol 3, 4. Lief. (Erganzung). Quelle \& Meyer, Leipzig, 45-134.

Sellnick M (1928) Formenkreis: Hornmilben, Oribatei. In: Brohmers P, Ehrmann P, Ulmer G (Eds) Die Tierwelt Mitteleuropas Vol. 3, 4. Lief. (Teil 9). Quelle \& Meyer, Leipzig, 1-41. Siepel H (1996) The importance of unpredictable and short-term environmental extremes for biodiversity in oribatid mites. Biodiversity Letters 3(1): 26-34. doi: 10.2307/2999707

Subías LS (2004) Listado sistemático, sinonímico y biogeográfico de los Ácaros Oribátidos (Acariformes, Oribatida) del mundo (1758-2002). Graellsia 60: 3-305.

Willmann C (1931) Moosmilben oder Oribatiden (Oribatei). In: Dahl F (Eds) Die Tierwelt Deutschland und der angrenzenden Meeresteile. Verlag Gustav Fisher, Jena, 79-200. 